\section{An investigation of current endodontic practice and training needs in primary care in the north west of England}

\author{
N. O. A. Palmer, ${ }^{1}$ M. Ahmed ${ }^{2}$ and B. Grieveson ${ }^{3}$
}

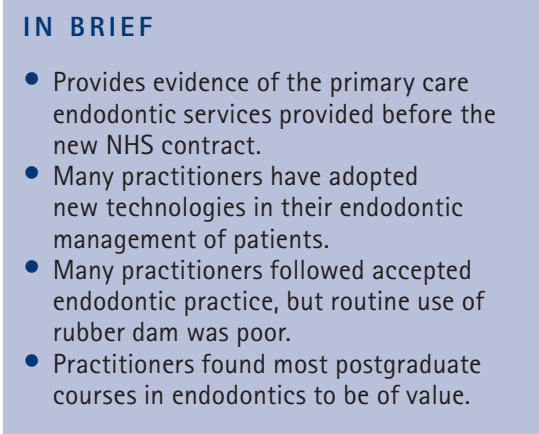

\begin{abstract}
Objective To investigate current endodontic clinical practice in the north west of England and evaluate practitioner's training needs. Method A questionnaire was posted to 702 primary care dentists in the north west of England in January 2006. The questionnaire investigated aspects of dentists' endodontic clinical practice, the provision of endodontics within their practice, their recent postgraduate training in endodontics and their training needs. Results Responses to the questionnaire were received from 498 (70.9\%) primary care dentists, of which 449 questionnaires contained useful information. Only $30 \%$ of respondents use rubber dam for isolation in all endodontic cases. The majority used radiographs either as the only method for establishing the working length (57.3\%) or in conjunction with an apex locator (34.5\%). Most dentists used sodium hypochlorite solution as an irrigant during the root canal treatment. Almost 55\% used a combination of conventional hand files and rotary files to prepare root canals. Fifty-eight percent used the crown down technique while $35 \%$ used the step back technique for canal preparation. Almost two-thirds routinely used non-setting calcium hydroxide as an intra-canal medicament. Lateral condensation technique was the popular obturation method and the vast majority of respondents routinely took postoperative radiographs. Almost $25 \%$ of respondents had not received any teaching or training in endodontics in the past two years. Conclusions The results of this study suggest that primary care dentists in the north west of England have embraced modern techniques and follow most aspects of accepted endodontic practice. Despite the majority having postgraduate training in the last two years, only a minority used rubber dam routinely for endodontic treatment.
\end{abstract}

\section{INTRODUCTION}

The number of root fillings provided under the National Health Service (NHS) in England and Wales in 2004-2005 was 927,500 at a cost of approximately £50 million. ${ }^{1}$ A meta-analysis of the success rates for conventional endodontic treatment reported success as between $78-84 \%{ }^{2}$ Micro-organisms colonising root canals play a major role in pulpal and periapical disease and the success of endodontic treatment is, in part, due to the techniques

\footnotetext{
1*General Dental Practitioner/Research Associate, Mersey Deanery, 4 Dowhills Road, Blundellsands, Liverpool, L23 8SN; ${ }^{2}$ Specialist Registrar in Restorative Dentistry, Liverpool University Dental Hospital, Liverpool, L3 5PS; ${ }^{3}$ Postgraduate Dental Dean, Mersey Deanery, Liverpool, L3 4BN

${ }^{*}$ Correspondence to: Dr N. O. A. Palmer Email: Nikolaus.Palmer@btinternet.com
}

\section{Online article number E22}

Refereed Paper - accepted 5 February 2009

DOI: $10.1038 /$ sj.bdj.2009.473

${ }^{\circledR}$ British Dental Journal 2009; 206: E22 employed in removing intra-radicular bacteria. $^{3}$ Therefore isolation, biomechanical preparation, obturation along with temporisation and final restoration can have an impact on the long-term success of root filled teeth. ${ }^{4-7}$

The past 10-15 years have witnessed significant changes in the practice of endodontics. The microscope, ultrasonic units with specially configured tips, apex locators and flexible nickel-titanium files in rotary engines have changed the way endodontics is practised. These key advances in endodontics should enable dentists to achieve successful treatment outcomes more efficiently by minimising procedural errors, reducing chairside time and discomfort to the patient. ${ }^{8,9}$

Previous studies have investigated endodontic techniques used in dental practice both in the United Kingdom (UK) and abroad. ${ }^{10-16}$ These studies focused on specific areas of endodontic technique, for example use of rubber dam, the type of irrigant used and temporarisation. Very few studies have investigated all aspects of endodontic practice including provision of endodontic treatment, postgraduate education and training needs. The aims of this study were to investigate current endodontic clinical practice in an area of the north west of England, to identify factors affecting clinical provision of endodontic treatment, practitioners' postgraduate education in endodontics and their training needs.

\section{METHOD}

A questionnaire was devised to investigate dental practitioners' current endodontic practice within primary dental care. The questionnaire comprised of four parts: the first part consisted of the personal details of the respondent (for example, age, gender), their main job within dentistry, year and place of qualification. No personal data were collected to ensure anonymity of the responses. 
The second part investigated primary care dentists' provision of endodontics within their practice; whether they treated both single and multi-rooted teeth and any factors influencing their clinical practice. This section of the questionnaire also investigated referral patterns, specifically the reasons for referral and to whom.

The third part of the questionnaire investigated in detail the clinical methods used when providing endodontic treatment. The areas investigated included methods of isolation and instrumentation, the types of instruments and medicaments used, methods of obturation, aspects of radiography and the final restoration.

The final part of the questionnaire investigated recent postgraduate training in endodontics; what form this had taken and whether it had been of value and influenced their current practice. This part of the questionnaire also investigated primary care dentists' perceived future training needs.

The questionnaire was piloted to dentists outside the geographical area of the study. These dentists were asked to comment on the structure, content and ease of completion. The questionnaire was modified and sent to all primary care practitioners held on a mailing list at the Mersey Postgraduate Deanery in January 2006 with a covering letter stating the aims of the questionnaire. All questionnaires were tracked by means of an identification number which facilitated follow-up of non-responders. Following the initial mailing, two further mailings were sent followed by telephone reminders to non-responders to improve the response rate.

All the useable responses were coded and entered into a Statistical Package for Social Science (SPSS) database (SPSS for Windows Base Version 11.0.0 version. SPSS Inc, Chigaco, IL 60611, USA) and the frequencies of the responses for each question were calculated. Statistical tests were carried out to determine if there were any significant relationships between age groups, gender, university of qualification and the use of rubber dam, irrigant used and the use of rotary instruments.

\section{RESULTS}

Of the 702 questionnaires distributed to primary care practitioners 498 were returned, producing a response rate of

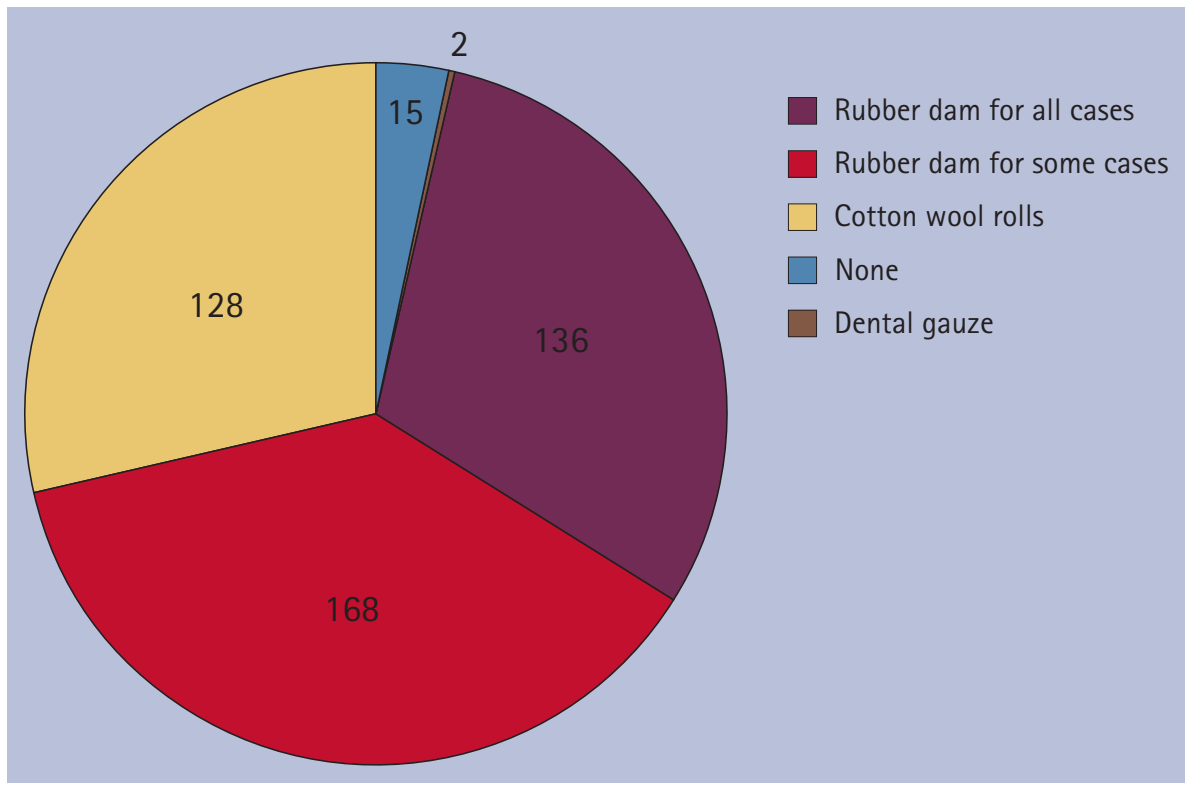

Fig. 1 The number of primary care practitioners using different methods of isolation $(n=449)$

70.9\%; 49 questionnaires were returned incomplete resulting in 449 usable replies. Of the respondents $64.7 \%$ were male and $35.3 \%$ female and there was an even distribution within age groups (25-30 years, 31-40 years, 41-50 years, 51-60 years) apart from the $60+$ years of age group.

Over 50\% (227) of the respondents qualified at Liverpool Dental School, but all the UK dental schools were represented, with $3.8 \%$ (17) qualifying overseas. Nearly $90 \%$ (396) of the respondents worked in NHS general practice, 9.8\% (44) were private practitioners, $1.2 \%$ (6) worked in the community dental service and only two practitioners worked in specialist endodontic practice. Of the 449 respondents $96.9 \%$ (432) routinely carried out endodontic treatment. There was a wide range in the total number of completed treatments per month, ranging from 0-30+, with 90.8\% (404) completing between 0-20 treatments per month, 7.2\% (32) between 21-30 treatments per month and the remainder more than 30 treatments per month. Only 6.9\% (31) of the respondents did not treat multirooted teeth. The reasons given by the 31 dentists for not treating multi-rooted teeth were inadequate fees for 16 of the dentists; for 5 dentists it was the time taken to complete treatment, and for the remainder a lack of equipment and lack of training.

Of the 323 respondents who would refer patients for endodontic treatment 70.8\% (229) would refer to a specialist working in primary care, $11.6 \%$ (52) to a hospital consultant and 9.4\% (42) to a dental practitioner with a special interest (DwSI). The reasons given for referral by the 323 dentists who did refer included difficult root morphology $(52 \%, 68)$, re-treatments $(28.5 \%, 92)$ and obstructions in the root canal $(19.5 \%, 63)$.

\section{Isolation}

As shown in Figure 1 only 30.3\% (136) of the 449 respondents stated they used rubber dam isolation for endodontic treatment in all cases, whereas 37.4\% (168) used rubber dam to isolate some cases. Of the remaining respondents 29.4\% (132) used cotton wool rolls alone or with either dental napkins or butterfly sponges and $3.3 \%$ (15) replied that they used no form of isolation. There were no significant differences between age group, gender, university of qualification and the use of rubber dam ( $p$ >0.05).

\section{Working length}

The majority $(57.3 \%, 257)$ of the 449 dentists used radiographs either as the only method for establishing the working length or in conjunction with an apex locator (34.5\%, 155). Only 8.1\% (36) used an apex locator as the sole method to establish working length.

\section{Instruments}

Thirty-four percent (153) of the 449 responding dentists used conventional hand files only to prepare root canals, with 25.1\% (112) adopting rotary nickel titanium (NiTi) systems only for preparation. However, 54.1\% (243) used a combination 


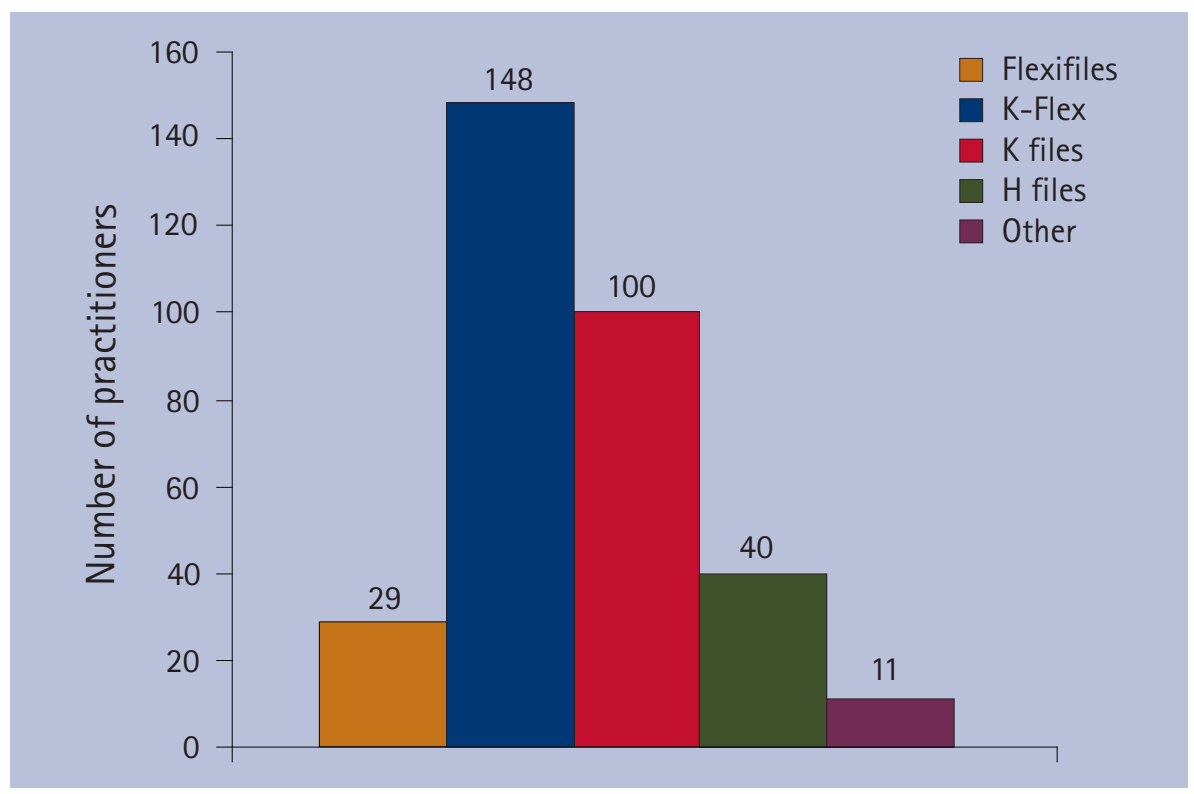

Fig. 2 The different types of conventional hand files used by primary care practitioners

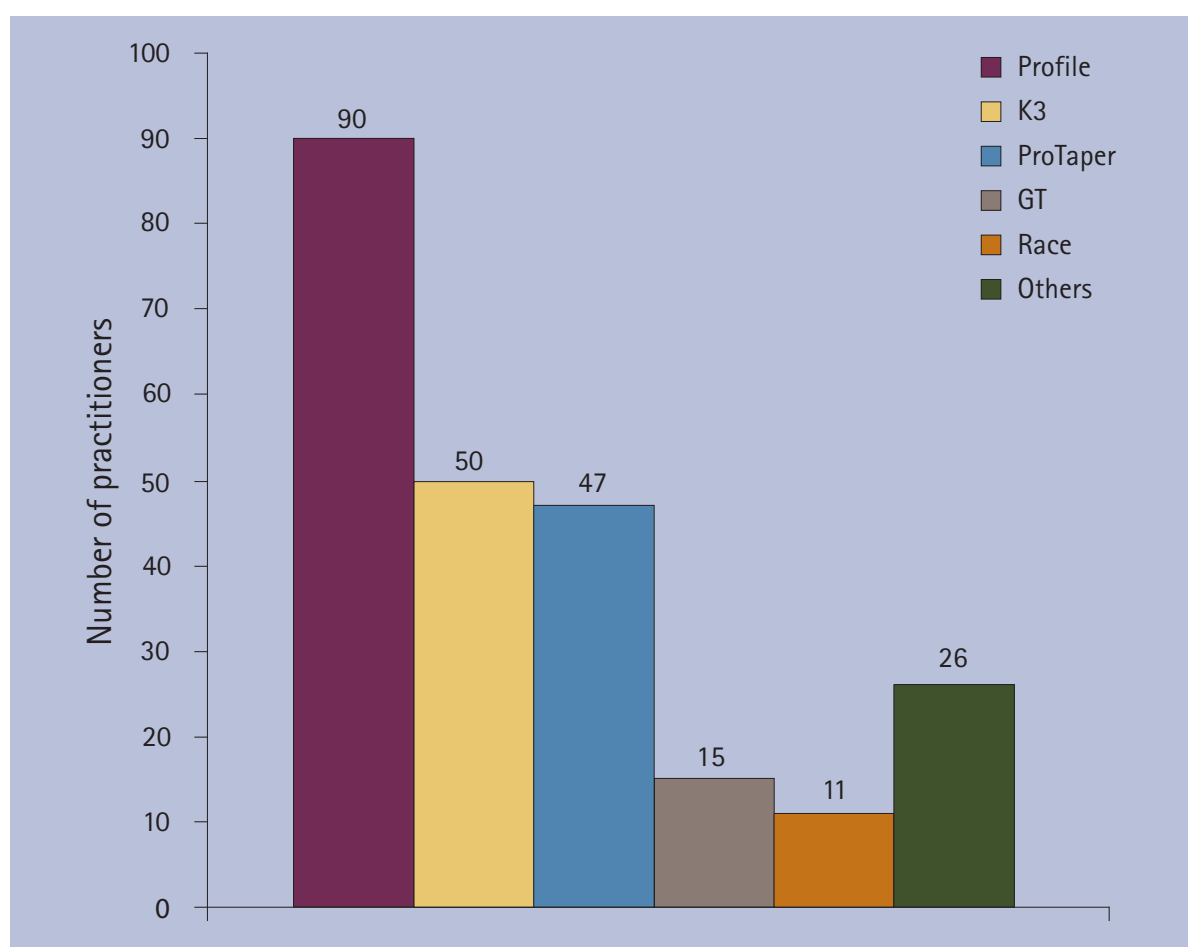

Fig. 3 The different types of rotary files used by primary care practitioners

of conventional hand files and rotary files. Over $70 \%$ of all the respondents used stainless steel Flexofiles ${ }^{\circledR}$ or $\mathrm{K}$ hand files. Profiles $^{\circledR}(24.3 \%)$, K3 (13.2\%), Protapers ${ }^{\circledR}$ (13.2\%) and System GT ${ }^{\circledR}(3.5 \%)$ were the most commonly used nickel titanium rotary files (Figs 2 and 3). There were no significant differences between age group, gender, university of qualification and the use of NiTi rotary files ( $p>0.05$ ).

\section{Irrigation solutions}

Sodium hypochlorite was the most common irrigant used $(75 \%, 336)$ and was the only irrigant used by $54.3 \%$ of the 449 respondents. Chlorhexidine was used by $28 \%$ (125) of the dentists, and was used to the exclusion of other irrigants by $11 \%$ (49). Smaller numbers used saline, local anaesthetic solution or super-oxidised water (Sterilox). There were no significant differences between age group, gender, university of qualification and the irrigant solution used ( $p>0.05$ )

\section{Preparation technique}

Fifty-eight percent (252) of the respondents stated they used the crown down technique, 35\% (152) used the step back technique with $6 \%$ using both techniques in preparing root canals before obturation. Almost two-thirds of respondents (61\%) completed single root canal treatment in two visits, $29 \%$ in one visit and the remaining $18 \%$ in three or more visits. Over half of the respondents (238) who performed multi-rooted endodontic treatment completed the procedure in two visits, 31\% (137) completed root canal treatment in molars in three or more visits with 9.8\% of practitioners completing molar endodontic treatment in one visit.

\section{Intra-canal medicaments}

Of all the 449 respondents, 60\% (269) routinely used non-setting calcium hydroxide as an intra-canal medicament. Some dentists used Ledermix ${ }^{\circledR}(19 \%, 85)$ or parachlorophenol $(13 \%, 58)$ and $3 \%(13)$ used medicaments such as cresophene or iodoform. Almost 5\% (22) stated that they did not use any intra-canal medication between visits.

\section{Obturation technique}

Almost three-quarters of the 449 respondents (319) routinely used the lateral condensation technique, while 12\% (54) used a single cone technique. The remainder used either Thermafil ${ }^{\circledR}(8.9 \%)$ or System $\mathrm{B}^{\mathrm{TM}}$ and Obtura ${ }^{\circledR}(2.7 \%)$. Tubliseal ${ }^{\mathrm{TM}}$ was the most common root canal sealer used (251, 56\%) with calcium hydroxide-based sealers (Apexit@ and Sealapex ${ }^{\mathrm{TM}}$ ) used by $36 \%$ (161) of respondents.

\section{Number of radiographs}

The vast majority of the 449 respondents routinely took preoperative and postoperative radiographs $(97.5 \%$ and $95.2 \%$ respectively) to check root morphology and the final root filling following obturation. When asked how many radiographs in total were taken during endodontic treatment of a tooth, more than half (53.8\%) of the respondents took three radiographs, 44\% took two radiographs and a small number of practitioners took four radiographs.

\section{Placing of direct restoration following endodontic treatment}

Of all the practitioners who responded, 299 (66.6\%) would place a direct restoration immediately following completion of 
endodontic treatment. The remainder would leave placement to a later date. When asked about placing a crown or inlay/onlay following endodontic treatment there was a wide variation (7-240 days) in the time between completion of endodontic treatment and placement. Approximately 75\% of practitioners would place a crown or inlay/onlay within five weeks and over 90\% within three months.

\section{Training in endodontics in the past two years}

Almost one-quarter (104) of 449 respondents had not received any teaching or training in endodontics in the past two years. Of the other respondents, 47\% (211) had training in the form of didactic lectures, 22.2\% (100) had attended hands-on courses, and a smaller number had received their training through journals and e-learning (Fig. 4). The majority $(95.3 \%, 328)$ of the 344 respondents who had received training found their postgraduate experience in the last two years to have been of value, and $76.5 \%$ (264) stated that the training they had received had produced a change in their endodontic treatment management of patients. When asked about their future training needs nearly 25\% of practitioners wanted hands-on courses, specifically to teach modern techniques, molar endodontics and management of difficult cases.

\section{DISCUSSION}

To achieve as high a response rate as possible in this study a number of known strategies were used. ${ }^{17} \mathrm{~A}$ reminder was sent after two weeks to the dentists on the mailing list not responding to the first questionnaire. Non-responders were then telephoned and encouraged to complete the questionnaire. The resulting response rate of 70.9\% from a total of 702 questionnaires distributed was considered satisfactory. The distribution of male to female dentists and the age groups who responded closely mirrors the distribution of dentists working within the NHS. ${ }^{18}$ However, the majority of dentists responding to the questionnaire qualified at Liverpool Dental School and, for ease of administration, this study was confined to dentists practising within the boundaries of the Mersey Deanery. It is accepted therefore that there may be regional bias in the responses. The results are, nevertheless, of value in providing information on current

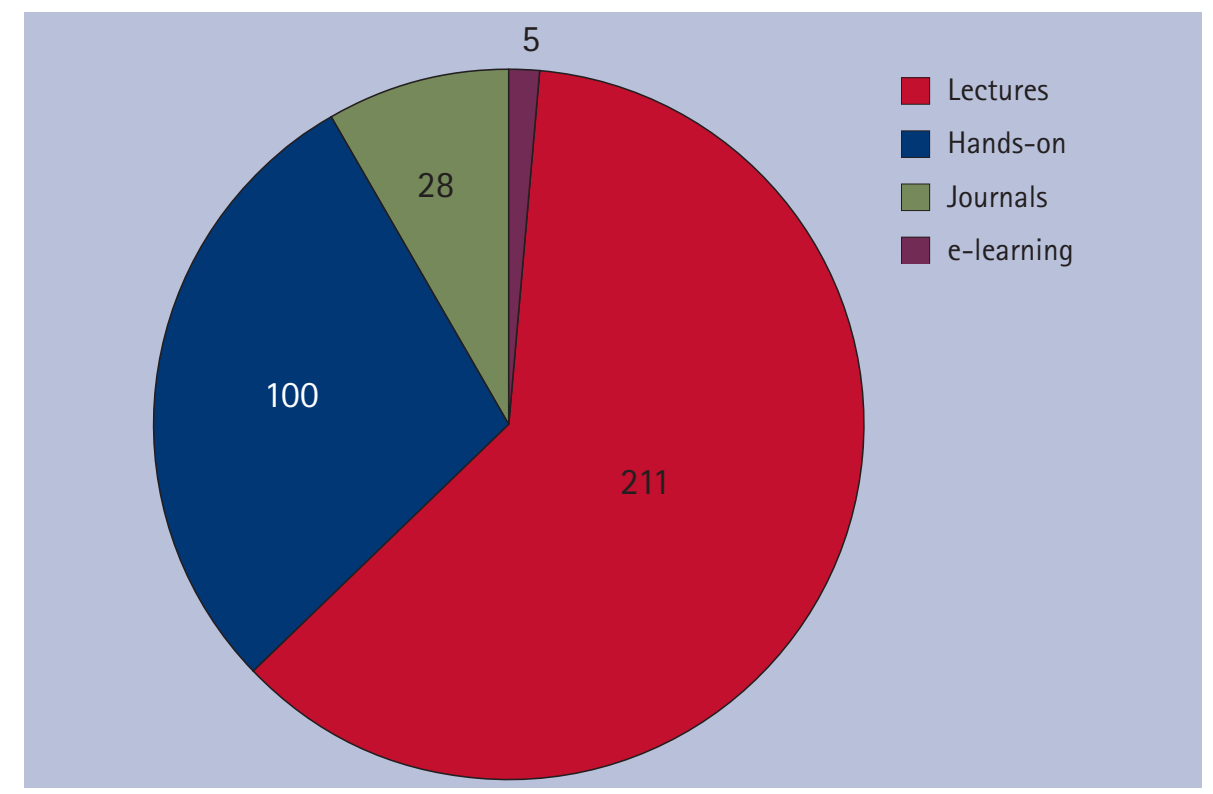

Fig. 4 The different methods of endodontic training experienced by primary care practitioners in the past two years $(n=344)$

endodontic practice and training needs.

Most primary care dentists in this study were providing NHS endodontic treatment, including the management of multi-rooted teeth, and it will be interesting to see if this continues as the new NHS contract for primary dental care beds in. It is accepted that the use of rubber dam in endodontic treatment reduces oral contamination and eradicates the risk of patients swallowing or inhaling root canal instruments or medicaments. In this study however, the percentage of dentists (30.3\%) who used rubber dam routinely for isolation was poor. This is all the more disturbing because a large number of the respondents in this study (75\%) use sodium hypochlorite as their choice of irrigant and the majority use hand files for preparing the canals. This study confirms the findings of earlier studies that the use of rubber dam is still, despite the conclusions of previous studies, largely neglected by dental practitioners in the UK. ${ }^{15,16}$ Some studies suggest that although some dentists are using techniques taught during their undergraduate careers, a large percentage of dentists use techniques with no evidence of clinical effectiveness and not taught during the undergraduate course. ${ }^{15,16}$ The barriers to use of rubber dam have been investigated in the past and it was concluded that patients did not like it, that the NHS fees were inadequate, it took too long and dentists had inadequate training. ${ }^{16}$ It is clear that although this was not an area highlighted by those taking part in the study, further education in this area of endodontic treatment is required.

Accurate determination of root canal length is an important step in the success of endodontic treatment. Several in vitro and in vivo studies have shown the reliability of electronic apex locators in establishing the working length. ${ }^{19-21}$ The present study showed that over $40 \%$ of practitioners use an apex locator during endodontic treatment but only $8 \%$ would use it as the only method to confirm the canal length. The benefit of reducing the number of radiographs and reducing radiation exposure to the patient would appear to be lost on the majority in this study who do not use an apex locator for determining working length. ${ }^{22}$ Further research is required to investigate why electronic apex locators are not generally accepted as the sole method of determining canal length.

Previous studies seem to indicate that the use of nickel titanium rotary instrumentation facilitates root canal preparation and makes it easier to produce good quality root fillings. ${ }^{23}$ A survey revealed that only $10 \%$ of dentists in Denmark had adopted rotary instrumentation ${ }^{24}$ and in another study only $22 \%$ of the general practitioners in Australia reported using rotary systems for canal preparations. ${ }^{11}$ It was encouraging to see in this present study the adoption of nickel titanium (NiTi) rotary instruments by more than half of the dentists. However, a recent communication to all dentists in 
England and Wales from the Chief Dental Officer of England stated that all endodontic files should be considered single use because of the possible risk of transmission of variant Creutzfeldt-Jakob disease. ${ }^{25}$ This may produce a cost pressure on the continuing use of rotary NiTi instruments in NHS general practice and may affect the provision and quality outcomes of endodontic treatment. This is an area that will require further investigation.

Among the irrigants used, sodium hypochlorite was the most commonly used during root canal preparation. The use of sodium hypochlorite is accepted practice ${ }^{26}$ with studies showing that it reduces the number of bacterial cells in the root canal and dissolves organic debris. ${ }^{27}$ It has also been shown that using a combination of sodium hypochlorite and chlorhexidine gives the greatest bacterial reduction within the root canal. ${ }^{28}$ Sodium hypochlorite can however be toxic ${ }^{29,30}$ and reduces bond strength to root canal dentine. ${ }^{31}$ This may have influenced a number of dentists who use other agents such as chlorhexidine, saline, local anaesthetic or super-oxidised water (Sterilox). Super-oxidised water has been shown to be effective in root treatment and may be an alternative irrigant to sodium hypochlorite. ${ }^{32}$ Chlorhexidine solution alone has been shown to be effective in removing Enterococcus faecalis, a micro-organism commonly associated with persistent endodontic infections. ${ }^{33}$

The type of intracanal medicament used by dentists in this study was diverse. The use of non-setting calcium hydroxide is accepted practice, with studies showing that calcium hydroxide used as an intracanal medicament renders most canals bacteria-free following biomechanical preparation and that it is superior to Ledermix ${ }^{\circledR} .^{34,35}$ But it has also been demonstrated that Ledermix ${ }^{\circledR}$ is an effective intracanal medicament for the control of postoperative pain associated with acute apical periodontitis. ${ }^{36}$

Canal obturation was mainly with gutta percha and sealer, with the majority of respondents preferring to use cold lateral condensation technique to obturate the root canal. This technique is widely used and still considered by some clinicians and researchers as the gold standard, despite the criticism that it does not produce a homogenous filling, leaving gaps and voids..$^{37,38}$
Among the other techniques used was Thermafil Plus ${ }^{\circledR}$, which utilises warmed gutta percha encased around a plastic carrier. Although the technique is simple and usually produces fewer voids, it may result in canal overfilling. ${ }^{39}$ Only a small percentage of respondents used thermoplastised techniques such as System $B^{\text {TM }}$ and Obtura ${ }^{\circledR}$. Although the reasons for only a small number using these techniques was not investigated in this study, it may be due to the cost of equipment and the lack of training.

The success rate of endodontically treated teeth is affected by the coronal seal. ${ }^{40}$ Sealers used do not prevent microleakage coronally and therefore the placement of a definitive restoration following obturation is important. ${ }^{41}$ It has been shown that the time of placement is crucial, with a high success rate achievable when the final restoration is placed within a short period of time, usually about two weeks. ${ }^{42}$ Within the present study most practitioners would place a direct restoration almost immediately, but there was a wide variation in time between completion of root treatment and placing a crown or onlay. This may predispose to failure of the root treatment in the future.

Endodontics is a significant treatment modality within primary care dentistry. ${ }^{1}$ With the advance in materials and techniques there is a need for practitioners to continually update their knowledge and skills to comply with the standards set by the General Dental Council. ${ }^{43}$ This study also investigated dentists' attendance at postgraduate training courses for modern endodontic techniques and showed that 25\% had not updated their knowledge and skills in endodontics within the last two years. It was reassuring that those who had attended courses found their training to be of value and had incorporated changes into the management of patients. Further research is required to assess whether changes, as a result of education, improve the standard of treatment delivered.

A study investigating endodontic standards in general dental practice identified that hands-on courses were the preferred method of delivery for endodontic training and that practitioners had a great desire to improve their endodontic techniques. ${ }^{44}$ It is evident from this study that there is a continuing requirement to provide training, especially hands-on courses, in endodontic techniques and particularly the use of rubber dam.

\section{CONCLUSIONS}

This study has shown that most dentists in an area of the north west of England provide a comprehensive endodontic service to their patients and follow most aspects of accepted endodontic practice, apart from the use of rubber dam. A large number have also embraced the newer technologies into their practice which should improve the success rates of endodontically treated teeth and patient care. This study has also confirmed that the provision of courses in the past has been of value to practitioners, but that further training is required for practitioners in a number of areas. It is hoped that postgraduate departments will continue to provide funded courses, particularly hands-on courses, for practitioners in this technically challenging area of clinical dentistry.

1. NHS Business Services Authority Dental Practice Division. Annual digests of statistics 2004-2005. Eastbourne: National Health Service Business Services Authority, 2005.

2. Kojima $\mathrm{K}$, Inamoto $\mathrm{K}$, Nagamatsu $\mathrm{K}$ et al. Success rate of endodontic treatment of teeth with vital and nonvital pulps. A meta-analysis. Oral Surg Oral Med Oral Pathol Oral Radiol Endod 2004: 97: 95-99.

3. Sundqvist G. Associations between microbial species in dental root canal infections. Oral Microbiol Immunol 1992; 7: 257-262.

4. Barthel C R, Zaritzki F F, Raab W H, Zimmer S. Bacterial leakage in roots filled with different medicaments and sealed with Cavit. J Endod 2006; 32: $127-129$.

5. Gorni F G, Gagliani M M. The outcome of endodontic retreatment: a 2-yr follow-up. J Endod 2004; 30: 1-4.

6. Saunders W P, Saunders E M. Coronal leakage as a cause of failure in root-canal therapy: a review. Endod Dent Traumatol 1994; 10: 105-108.

7. Smith C S, Setchell D J, Harty F J. Factors influencing the success of conventional root canal therapy - a five-year retrospective study. Int Endod J 1993; 26: 321-333.

8. Guelzow A, Stamm 0, Martus P, Kielbassa A M. Comparative study of six rotary nickel-titanium systems and hand instrumentation for root canal preparation. Int Endod J 2005; 38: 743-752.

9. Schafer E, Schulz-Bongert U, Tulus G. Comparison of hand stainless steel and nickel titanium rotary instrumentation: a clinical study. J Endod 2004; 30: 432-435.

10. Vail M M, Steffel C L. Preference of temporary restorations and spacers: a survey of Diplomates of the American Board of Endodontists. J Endod 2006; 32: $513-515$.

11. Parashos P, Messer H H. Questionnaire survey on the use of rotary nickel-titanium endodontic instruments by Australian dentists. Int Endod J 2004; 37: 249-259.

12. Wilson N H, Christensen G J, Cheung S W, Burke F J, Brunton P A. Contemporary dental practice in the UK: aspects of direct restorations, endodontics and bleaching. Br Dent J 2004; 197: 753-756.

13. Hommez G M, De Moor R J, Braem M. Endodontic treatment performed by Flemish dentists. Part 2. Canal filling and decision making for referrals and 
treatment of apical periodontitis. Int Endod J 2003; 36: 344-351.

14. Slaus $G$, Bottenberg P. A survey of endodontic practice among Flemish dentists. Int Endod J 2002; 35: 759-767.

15. Jenkins S M, Hayes S J, Dummer PM. A study of endodontic treatment carried out in dental practice within the UK. Int Endod J 2001; 34: 16-22.

16. Whitworth J M, Seccombe G V, Shoker K, Steele J G. Use of rubber dam and irrigant selection in UK general dental practice. Int Endod J 2000; 33: 435-441.

17. Edwards P, Roberts I, Clarke M et al. Methods to increase response rates to postal questionnaires. Cochrane Database Syst Rev 2007; (2): R000008. DOI: 10.1002/14651:858.MR000008.pub3.

18. The Information Centre. NHS dental statistics for England: 2006/2007. London: The Information Centre, 2007. http://www.ic.nhs.uk/webfiles/publications/dental0607/NHS\%20Dental\%20Statistics\%20 for\%20England\%202006-07.pdf.

19. Balto H A, Al-Madi E M. A comparison of retreatment decisions among general dental practitioners and endodontists. J Dent Educ 2004; 68: 872-879.

20. Smadi L M. Comparison between two methods of working length determination and its effect on radiographic extent of root canal filling: a clinical study. BMC Oral Health 2006; $6: 4$.

21. Hoer D, Attin T. The accuracy of electronic working length determination. Int Endod J 2004; 37: 125-131.

22. Fouad A F, Reid L C. Effect of using electronic apex locators on selected endodontic treatment parameters. J Endod 2000; 26: 364-367.

23. Gluskin A H, Brown D C, Buchanan LS. A reconstructed computerized tomographic comparison of $\mathrm{Ni}$-Ti rotary GT files versus traditional instruments in canals shaped by novice operators. Int Endod J 2001; 34: 476-484

24. Bjorndal $L$, Reit $C$. The adoption of new endodontic technology among Danish general dental practitioners. Int Endod J 2005; 38: 52-58.
25. Department of Health. Advice for dentists on reuse of dental instruments and variant CreutzfeldtJakob disease (VCJD). London: Department of Health, 2007. http://www.dh.gov.uk/en/ Publicationsandstatistic s/Lettersandcirculars/ Dearcolleagueletters/DH_074001.

26. Averbach R E, Kleier D J. Clinical update on root canal disinfection. Compend Contin Educ Dent 2006; 27: 284, 286-289.

27. Siqueira J F, Jr, Rocas I N, Favieri A, Lima K C. Chemomechanical reduction of the bacterial population in the root canal after instrumentation and irrigation with $1 \%, 2.5 \%$, and $5.25 \%$ sodium hypochlorite. J Endod 2000; 26: 331-334.

28. Zamany A, Safavi K, Spangberg LS. The effect of chlorhexidine as an endodontic disinfectant. Oral Surg Oral Med Oral Pathol Oral Radiol Endod 2003; 96: 578-581.

29. Witton R, Brennan P A. Severe tissue damage and neurological deficit following extravasation of sodium hypochlorite solution during routine endodontic treatment. Br Dent J 2005; 198: 749-750.

30. Gernhardt C R, Eppendorf K, Kozlowski A, Brandt M. Toxicity of concentrated sodium hypochlorite used as an endodontic irrigant. Int Endod J 2004; 37: 272-280.

31. Erdemir A, Ari H, Gungunes $H$, Belli S. Effect of medications for root canal treatment on bonding to root canal dentin. J Endod 2004; 30: 113-116.

32. Solovyeva A M, Dummer P M. Cleaning effectiveness of root canal irrigation with electrochemically activated anolyte and catholyte solutions: a pilot study. Int Endod J 2000; 33: 494-504.

33. Stuart C H, Schwartz S A, Beeson T J, Owatz C B. Enterococcus faecalis: its role in root canal treatment failure and current concepts in retreatment. $J$ Endod 2006; 32: 93-98.

34. Chu F C, Leung W K, Tsang P C, Chow T W, Samaranayake L P. Identification of cultivable microorganisms from root canals with apical periodontitis following two-visit endodontic treatment with antibiotics/steroid or calcium hydroxide dressings. J Endod 2006; 32: 17-23.

35. de Souza C A, Teles R P, Souto R, Chaves M A Colombo A P. Endodontic therapy associated with calcium hydroxide as an intracanal dressing: microbiologic evaluation by the checkerboard DNA-DNA hybridization technique. J Endod 2005; 31: 79-83.

36. Ehrmann E H, Messer H H, Adams G G. The relationship of intracanal medicaments to postoperative pain in endodontics. Int Endod J 2003; 36: 868-875

37. Clinton K, Van Himel T. Comparison of a warm gutta-percha obturation technique and lateral condensation. J Endod 2001; 27: 692-695.

38. Weller R N, Kimbrough W F, Anderson R W. A comparison of thermoplastic obturation techniques: adaptation to the canal walls. J Endod 1997; 23: 703-706.

39. Da Silva D, Endal U, Reynaud A, Portenier I, Orstavik D. Haapasalo M. A comparative study of lateral condensation, heat-softened gutta-percha, and a modified master cone heat-softened backfilling technique. Int Endod J 2002; 35: 1005-1011.

40. Hommez G M, Coppens C R, De Moor R J. Periapical health related to the quality of coronal restorations and root fillings. Int Endod J 2002; 35: 680-689.

41. Kopper P M, Figueiredo J A, Della Bona A, Vanni $J \mathrm{R}$, Bier C A, Bopp S. Comparative in vivo analysis of the sealing ability of three endodontic sealers in post-prepared root canals. Int Endod J 2003; 36: 857-863.

42. Willershausen $B$, Tekyatan $H$, Krummenauer $F$, Briseno Marroquin B. Survival rate of endodontically treated teeth in relation to conservative vs post insertion techniques--a retrospective study. Eur J Med Res 2005; 10: 204-208.

43. General Dental Council. Standards for dental professionals. London: General Dental Council, 2005.

44. Stewardson D A. Endodontic standards in genera dental practice-a survey in Birmingham, U K, Part 2. Eur J Prosthodont Restor Dent 2001; 9: 113-116 